\title{
Por amor al arte
}

\author{
Ana Isabel Castro Carbonell | historiadora
}

URL de la contribución <www.iaph.es/revistaph/index.php/revistaph/article/view/4564>

Es bien sabido que el refranero español, haciendo gala del ingenio y del finísimo sentido de la ironía que lo caracteriza, recoge un buen número de frases hechas que encierran verdades antológicas, de las más cotidianas a las más sórdidas. Todas estas fórmulas actúan, a menudo, como "trajes a medida" de ciertas circunstancias y paradojas que se reflejan en todos los niveles de la realidad. Acciones que bajo la certeza del error humano se repiten como testigos de los aciertos, pero también de los fiascos colectivos que atribuimos a nuestro tiempo.

De todas ellas, la expresión que posiblemente mejor recoge la problemática planteada en el presente debate es la archiconocida hacer las cosas "por amor al arte". No en vano contempla la primera idea que acude a la mente del ciudadano medio cuando piensa de forma amplia en el patrimonio cultural, pero también en la legitimidad -o incongruencia- de los esfuerzos profesionales para su preservación y difusión, incluidos aquellos relativos a su rentabilidad y financiación.

En la base misma de dicho interés se encuentra la necesidad de definir a qué nos referimos cuando utilizamos algunos de los conceptos que aquí nos ocupan; en otras palabras: fijar los límites de la gestión de los bienes culturales -en cualquiera de sus formas- cuando éstos se convierten recursos susceptibles de monetización. Hablar de mecenazgo cultural o patrocinio exige conocer previamente las principales vías a través de las cuales se administran los recursos. Establecer y tener la capacidad de ejecutar las estrategias que a corto y medio plazo garanticen dotación económica y, sobre todo, la preservación efectiva frente al abandono y la destrucción.

\section{Manos que dan}

Con frecuencia confundimos el patrocinio, el mecenazgo o el crowdfunding con el altruismo; esto es: con la cua-

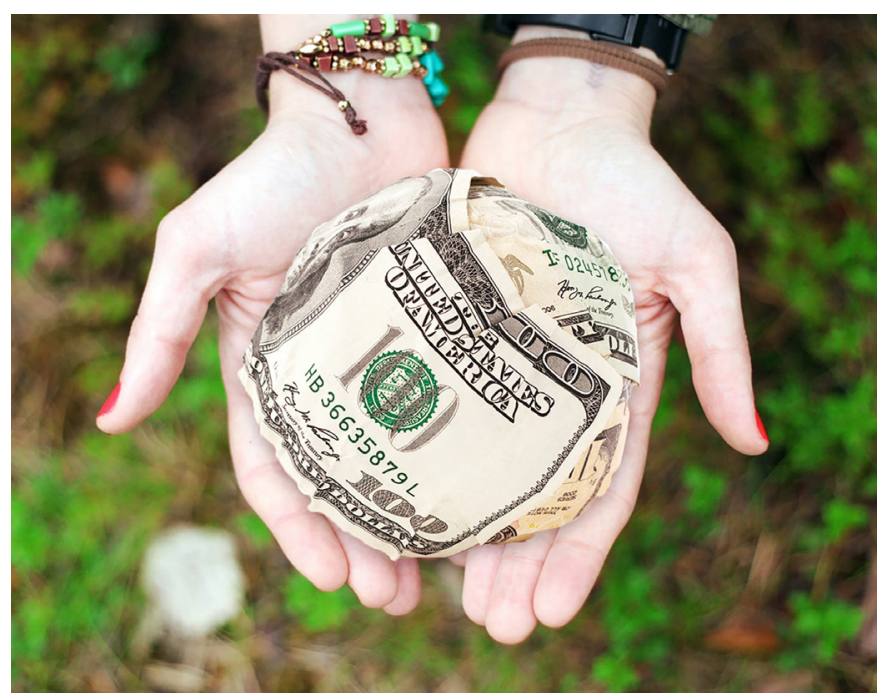

fuente pixabay

lidad de procurar un bien a algo o a alguien de forma desinteresada. Las muestras de altruismo pueden manifestarse a título particular - a través de una determinada acción sufragada por un particular-, o bien de forma colectiva -mediante la participación de varios agentes-. Ahora bien, todas estas ideas son complejas y están sujetas a los nuevos paradigmas de la comunicación de masas, por lo que requieren una lectura que rebasa lo meramente filantrópico. Mientras que el mecenazgo se proyecta sin fines lucrativos respecto a ciertas entidades e instituciones, el patrocinio y la esponsorización buscan recuperar parte del capital invertido en éstas mediante una presencia corporativa o imagen de marca. En este punto, entra en juego la importancia de la comunicación como nexo entre un agente que podríamos considerar activo y otro pasivo. Una vinculación promovida, a todas luces, por la complementariedad y beneficio mutuo (SÁNCHEZ DEL PERAL LÓPEZ, 2001).

En segundo lugar, se encontrarían las plataformas de financiación participativa (micromecenazgo o crowd- 
a debate Patrocinio, mecenazgo, crowdfunding ¿compromiso social o marketing interesado?

| coordina Ana Isabel Velasco Rebollo

funding). Frente a los conceptos que hemos visto anteriormente, recogerían aquellos esfuerzos económicos planteados a pequeña escala, de manera que el apoyo logrado revertiría en el inversor mediante recompensas. El principal problema que plantean es su carácter volátil y una dinámica de promoción más vinculada a la publicidad (por lo tanto, a una utilidad efímera e insostenible en el tiempo).

\section{Manos que reciben}

En otro orden de ideas, cabría calibrar el peso de una Ley de Mecenazgo capaz de promover y regular el diálogo efectivo entre las fundaciones españolas y los bienes culturales a escala local, autonómica y estatal. Sobre el precedente de la Ley 49/2002 de régimen fiscal de las entidades sin fines lucrativos y de los incentivos fiscales al mecenazgo, debe existir una legislación capaz de arbitrar ese contacto y que no se preste al abuso por parte de las entidades. Ello incluye disposiciones adicionales que garanticen que los fundadores, asociados, patronos y representantes estatuarios promuevan "fines de interés general" y destinen los rendimientos obtenidos a los objetivos preestablecidos. Del mismo modo, en lo referido al impuesto sobre sociedades, que las explotaciones económicas vinculadas a la investigación y las tareas propias de la cultura obtengan lo dispuesto por la normativa y puedan acogerse a un régimen fiscal especial. En definitiva, que la normativa funcione a su vez como contenedor de la acción particular, pero también como código ético y deontológico de la misma por hallarse ésta sujeta a unas motivaciones beneficiosas para la sociedad. Idéntica necesidad de regular esa interdependencia consideramos que debería aplicarse con el micromecenazgo, un terreno plagado de claroscuros.

Ambas cuestiones nos permiten extraer una lectura global: aunque observamos cómo el punto de partida puede llegar a ser el mismo, la motivación práctica es distinta. Eso justifica la atención desigual que recibe el legado patrimonial según su naturaleza, pero también un hecho más grave y aún más difícil de atajar: la infrafinanciación de lo público -acompañada con frecuencia de desidia por parte de la administración-, especialmente cuando ésta entra en un conflicto de intereses a la hora de justificar el capital pecuniario. Sólo así se explica que no exista una relación directa e inequívoca entre el mecenazgo y su repercusión social real.

Como conclusión, todos estos aspectos constituyen un reto constante en materia patrimonial desde un punto de vista normativo, pero también ético. No olvidemos que la ideología lo impregna todo, también cuando se trata de conservar y restaurar, de ahí la importancia de la figura profesional del gestor del patrimonio como agente mediador a quien le corresponde definir el valor de los bienes, pero también el vínculo formidable entre el pasado y el presente a través de la incomprendida voluntad de hacer las cosas "por amor al arte". Lo justo para medir, como poco, el nivel de concienciación de la ciudadanía.

\section{BIBLIOGRAFÍA}

- LEY 49/2002, de 23 de diciembre, de régimen fiscal de las entidades sin fines lucrativos y de los incentivos fiscales al mecenazgo. Boletín Oficial del Estado, n. ${ }^{\circ} 307$, de 24 de diciembre de 2002 <https://www.boe.es/buscar/doc. php?id=BOE-A-2002-25039> [Consulta: 19/12/2019]

- SÁNCHEZ DEL PERAL LÓPEZ, M. a C. (2001) El patrimonio cultural: Reflexiones sobre su tratamiento en cuestiones de mecenazgo y patrocinio. Boletín jurídico de la Universidad Europea de Madrid [en línea], n. ${ }^{\circ} 4$ <https://dialnet.unirioja.es/ revista/1513/A/2001> [Consulta: 19/12/2019] 